\title{
O CINEMA ETNOGRÁFICO DE JEAN ROUCH
}

\author{
EL CINE ETNOGRÁFICO DE JEAN ROUCH \\ THE ETHNOGRAPHIC CINEMA OF JEAN ROUCH
}

Maurício MIOTTI ${ }^{1}$

RESUMO: Jean Rouch desenvolveu em sua obra filmico-etnográfica um novo modo de se fazer cinema e antropologia, fornecendo possibilidades para ambos os campos. Este artigo busca, através de um estudo em antropologia visual, apresentar os modos como os filmes documentários de Robert Flaherty e Dziga Vertov influenciaram o trabalho de Jean Rouch, além de demonstrar as principais características e filmes de Jean Rouch e os conceitos desenvolvidos em sua obra. Portanto, este trabalho tem a intenção de ser uma introdução ao cinema etnográfico rouchiano, de modo a possibilitar um primeiro contato com a obra deste antropólogo-cineasta.

PALAVRAS-CHAVE: Antropologia visual. Cinema etnográfico. Jean Rouch.

RESUMEN: Jean Rouch desarrolló en su trabajo cine etnográfico una nueva forma de hacer cine y antropología, proveyendo posibilidades para los dos campos. Este artículo busca, mediante un estudio en antropología visual, presentar las formas en que los documentales de Robert Flaherty y Dziga Vertov influenciaron en la obra de Jean Rouch, además de demostrar las principales características, películas y los conceptos desarrollados en su obra. De tal modo, este trabajo pretende ser una introducción al cine etnográfico rouchiano, con el fin de posibilitar un primer contacto con la obra de este antropólogo-cineasta.

PALABRAS CLAVE: Antropologia visual. Cine etnográfico. Jean Rouch.

ABSTRACT: Jean Rouch developed in his film-ethnographic work a new way of making cinema and anthropology, providing possibilities for both fields. This article aims, through a study in visual anthropology, to present the ways in which the documentary films by Robert Flaherty and Dziga Vertov influenced the work of Jean Rouch, in addition to demonstrating the main characteristics and films of Jean Rouch, and the concepts developed in his works. Therefore, this work is intended to be an introduction to Rouchian ethnographic cinema, to provide a first contact with the work this anthropologist-filmmaker.

KEYWORDS: Visual anthropology. Ethnographic cinema. Jean Rouch.

${ }^{1}$ Universidade Estadual Paulista (UNESP), Araraquara - SP - Brasil. Mestrando no Programa de Pós-Graduação em Ciências Sociais. ORCID: https://orcid.org/0000-0001-9227-5420. E-mail: mauricio.miotti@unesp.br 


\section{Introdução}

O desenvolvimento da antropologia ocorreu paralelamente ao do cinema, sendo estabelecidos pontos de contato entre ambas. No entanto, a antropologia, a partir da década de 1930, se afasta da utilização de conteúdos visuais, por considerá-los permeados por subjetividades, o que os afastava da objetividade científica. Portanto, até os anos de 1950, o cinema etnográfico apresentou poucos trabalhos academicamente produtivos. Como nos mostra Novaes (2009, p. 47), “O único antropólogo a inovar efetivamente a partir do uso da câmera foi Jean Rouch". O antropólogo-cineasta desenvolve uma série de conceitos, os quais são impossíveis de compreender sem antes ter em mente que Rouch foi um antropólogo, mas não existe antropologia rouchiana sem levar em consideração a prática do cinema, estando os dois intrinsecamente ligados. Seus conceitos mais conhecidos são: antropologia compartilhada, cinema-verdade e etnoficção.

Contudo, para que possamos compreender a obra rouchiana, precisamos realizar um levantamento a partir de cineastas que exerceram influência sobre Jean Rouch: Robert Flaherty e Dziga Vertov. Além disso, deve-se também trazer para o interior da discussão alguns de seus filmes mais clássicos, como 'Os mestres loucos' ('Les maîtres fous', 1955), 'Eu, um negro' ('Moi, un noir', 1958) e 'Crônica de um verão' ('Chronique d'un été', 1961). Assim, este artigo busca apresentar uma introdução ao cinema etnográfico desenvolvido por Jean Rouch e aos principais conceitos engendrados no interior de sua obra.

\section{As influências de Flaherty e Vertov no cinema rouchiano}

Dois cineastas que exerceram influência no modo de fílmico-etnográfico rouchiano foram o estadunidense Robert Flaherty (1884-1951), realizador de 'Nanook, o Esquimó' ('Nanook of the North', 1922), e o soviético Dziga Vertov (1896-1954), realizador de 'Um homem com uma câmera' (1929).

A influência de Flaherty é percebida no uso da câmera participante, prática que possibilita a relação entre quem filma e quem é filmado, ou seja, o realizador "tomando parte não só de eventos registrados como também procurando refletir os registros a partir das perspectivas dos nativos - algo que Rouch inclusive tomará mais tarde como um dos seus principais paradigmas estéticos" (LESSA, 2014, p. 93). A perspectiva dos nativos sobre as imagens filmadas, tendo em vista a possibilidade de que Flaherty dispunha de exibir cenas do filme enquanto estava em campo, possibilita uma aproximação com a ideia de antropologia compartilhada desenvolvida posteriormente pelo próprio Rouch. 
Entretanto, há uma diferença marcante entre o cinema rouchiano e o cinema realizado por Flaherty. O estadunidense, como pode ser notado em 'Nanook', dispõe de uma câmera parada e fixa, limitação tecnológica imposta durante a época de realização do filme. Já no caso de Rouch, são realizadas inovações tecnológicas, como a possibilidade de filmar sem a utilização do tripé, como é mostrado por Sztutman (2004, p. 54): “Com Rouch, a câmera participante de Flaherty, entranhada no cotidiano dos filmados, ganha movimento e manipulação, tornando possível a construção de um discurso associado à experiência".

Além disso, a influência de Flaherty também se encontra no desenvolvimento de um cinema que filmasse o improvisado, no qual o nativo interpretaria a si mesmo e participaria da construção do filme. Essa última característica, como pode ser percebido, é algo muito perceptível nos filmes de etnoficção rouchianos. Flaherty também demonstrou a impossibilidade de filmar o real, fazendo um filme que buscava demonstrar como os Inuit viviam em um passado remoto, algo que pode ser demonstrado pelas cenas de caça, nas quais são usadas armas manuais, como lanças, mesmo que os sujeitos do filme já tivessem acesso a armas de fogo.

Já a presença de Vertov é percebida principalmente quando se trabalha com a questão da verdade do cinema. Em Vertov, o cinema era pensado como uma forma de construir, enquanto linguagem, e de se obter novas verdades, o que demonstraria a impossibilidade de filmar o real. Portanto, para Rouch "Não se trata mais do presente etnográfico inscrito no plano obtido pela câmera parada e fixa, como buscado por Flaherty, mas da cine-montagem como criação de uma situação e de um recorte, como haveria preconizado Vertov" (SZTUTMAN, 2004, p. 54). Ademais, isso fica claro em uma citação realizada por Sztutman (2004, p. 53) em seu artigo 'Jean Rouch: um antropólogo-cineasta', na qual reproduz uma entrevista de Jean Rouch, contida nos 'Cadernos de Antropologia e Imagem':

A expressão cinema-verdade vinha de um jogo de palavras para traduzir o nome do suplemento cinematográfico do Pravda, o jornal da verdade [...]. Mas ele [Vertov] entrou no jogo e fez uma frase que, para nós, se transformou na resposta para essa questão: "o cinema verdade não é a verdade no cinema, é a verdade do cinema”. Verdade particular! (Entrevista a Jean-Paul Colleyn, 1995, p. 68).

O realizador soviético também apresenta um pensamento cinematográfico no qual não há oposição entre ficção e documentário, inexistindo essas duas categorias. Defendia uma forma de arte que se afastava da literatura e do teatro, propondo que o cinema fosse uma linguagem em si, independente de outras formas de arte: 
Para Vertov, todo cinema verdadeiro estava sob a divisa do cine-olho e do kinopravda; todo outro cinema continuou sendo um prolongamento de romances e peças. Vertov não precisou cunhar um termo como "documentário", já que, para ele, seus filmes materializavam a essência do cinema, não os traços de um gênero. Ironicamente, o termo kinopravda voltaria a ser usado na homenagem feita a Vertov por Jean Rouch e Edgar Morin, quando batizaram sua nova forma de documentário de cinema verité (kinopravda em francês), como um tipo (ou modo) de documentário, em vez de uma categoria abrangente. O termo, que começou com Vertov como a definição de todo cinema verdadeiro, ficou associado não só com a área mais delimitada de um gênero, o documentário, mas também com o ainda mais delimitado subgênero do documentário participativo! (NICHOLS, 2012, p. 184 , grifo do autor).

Mesmo que se possa atribuir essa homenagem de Rouch e Morin a Vertov, o cinemaverdade rouchiano é influenciado também pelo próprio Flaherty, tal como demonstra Henley (2010), uma vez que, para Rouch, a verdade do cinema representava uma verdade que seria construída no momento da filmagem, através das ações do sujeito do filme, tendo em vista a presença da câmera, a qual alteraria os comportamentos dos indivíduos, indo além do cinemontagem.

\section{O cinema etnográfico de Jean Rouch}

Jean Rouch, após formar-se em engenharia, viajou para o continente africano a fim de exercer tal função. Entretanto, ao trabalhar durante os anos de 1940 na construção de estradas, se apaixonou pelas culturas diversas que encontrou por lá, tendo, inicialmente, interesse pelas temáticas da possessão, da magia e da feitiçaria, interesse este que acabou por ser demonstrado em alguns de seus filmes, como, por exemplo, 'Os mestres loucos'. Doutorou-se em etnografia sob orientação do etnógrafo francês Marcel Griaule (1898-1956) com a tese ' $L a$ religion et la magie Songhay'.

Entretanto, ao mesmo tempo em que realizava suas pesquisas etnográficas e desenvolvia sua tese, também fazia cinema, estando sua antropologia ligada ao cinema desde o início, sendo impossível estudar um sem considerar o outro: "Essa antropologia se revela pela prática cinematográfica, não se encontra jamais dela dissociada e pretende compor com ela um programa ético - daí a imbricação necessária, para Rouch, entre uma 'antropologia visual' e uma 'antropologia compartilhada"' (SZTUTMAN, 2004, p. 50).

Desse modo, Rouch era, em primeiro lugar, um antropólogo que fazia cinema, ou seja, um antropólogo-cineasta: “[...] a antropologia é seu verdadeiro ofício, ao passo que o cinema persiste como uma tarefa necessária" (SZTUTMAN, 2004, p. 50). 
Jean Rouch foi um antropólogo responsável por trazer diversas inovações a partir do uso da câmera em campo. Sylvia Caiuby Novaes mostra algumas dessas inovações, além de citar cineastas influenciados por esse novo modo de fazer cinema:

Inovou ao sugerir mudanças tecnológicas na câmera de filmar que permitissem seu uso sem o tripé e, portanto, mais próxima de seu foco de atenção, além de ter sido dos principais cineastas a fazer uso do som sincronizado. Mas a grande inovação de Jean Rouch para a antropologia foi propor a chamada antropologia compartilhada, em que os sujeitos da pesquisa participavam ativamente do processo de filmagem e edição. Seu "cine transe" acabou tendo muito mais influência sobre cineastas como Truffaut e Godard do que sobre antropólogos que realizavam filmes etnográficos (NOVAES, 2009, p. 47-48).

É necessário caracterizar mais profundamente esse estilo fílmico desenvolvido por Jean Rouch, o qual viria a desenvolver as principais características reivindicadas pelos autores da 'Nouvelle Vague': filmagens em cenários externos, sem uso de estúdios; ausência de um roteiro previamente escrito e de roteirista; presença de indivíduos comuns como atores; improviso e espontaneidade na realização das cenas; equipes pequenas; entre outras.

A filmagem sem tripé citada por Novaes, por exemplo, é algo introduzido por Rouch que possibilitou que a câmera seguisse os atores. Filmar sem o tripé possibilita que o cineasta se aproxime dos sujeitos, tanto no caso da pesquisa quanto no caso da arte. Desse modo, a própria câmera participa do filme, e, assim, pelo menos no que se refere ao cinema documentário e etnográfico, a presença daquele que filma se torna essencial para a construção da narrativa. A câmera em movimento será, após Rouch, utilizada por Jean-Luc Godard, por exemplo em 'Acossado' ('À bout de souffle', 1960).

Outra possibilidade apresentada pelo cinema etnográfico de Rouch, no caso da antropologia tal como citado por Novaes, foi o surgimento do conceito de antropologia compartilhada, uma antropologia em que os sujeitos da pesquisa teriam um papel ativo na construção do conhecimento antropológico. Entretanto, a realização desse tipo de trabalho etnográfico só foi possível através da junção entre antropologia e cinema:

A prática etnográfica associada ao cinema propiciaria o estabelecimento de uma antropologia compartilhada, alvo importante do trabalho desenvolvido por Jean Rouch, em tempos de revisão e crítica ao colonialismo, e, no caso específico do campo de Rouch, da descolonização e emancipação das nascentes nações africanas (BARBOSA; CUNHA, 2006, p. 36).

Assim sendo, da realização de uma antropologia compartilhada, da realização de um filme juntamente aos sujeitos pesquisados, resulta que "os filmes vão se tornando 
progressivamente uma produção coletiva da qual participam ativamente os atores-sujeitos, alguns dos quais se tornarão coautores" (HIKIJI, 2011, p. 116) e, portanto, os atores-sujeitos se tornam também coautores dos conhecimentos antropológicos produzidos.

Essa ideia fica evidente no filme 'Crônica de um verão', manifesto do cinemaverdade, realizado por Rouch em parceria com o sociólogo Edgar Morin, filme no qual se buscava demonstrar o cinema-verdade como um cinema no qual a verdade seria construída pela presença da câmera, a qual faria com que os indivíduos filmados agissem de uma determinada forma, o que não aconteceria se não fosse a ocorrência das filmagens. Portanto, tratava-se da verdade do cinema, e não, como se costumava acreditar, de uma verdade no cinema. Tratava-se não da reprodução do real, mas de uma realidade construída pelo filme, e, portanto, do cinema como uma forma de linguagem, capaz de produzir uma verdade própria, baseada na presença da câmera em campo e, após isto, no cine-montagem. Assim como constatado, a ideia de um cinema-verdade rouchiano demonstra a filiação de Jean Rouch a uma tradição do cinema documentário representada pelas figuras de Robert Flaherty e Dziga Vertov.

Em tal filme é possível ver o material filmado sendo mostrado aos sujeitos que participaram do filme, ao mesmo tempo em que é possível ter acesso ao que pensavam sobre suas performances de acordo com as imagens filmadas. Nessa cena em questão, os atores discutem se estariam agindo normalmente ou se estariam atuando, tendo em vista a presença da câmera. Desse modo, o que entra em questão seria a própria ideia da verdade e seu estatuto no produto cinematográfico.

Essa devolutiva das imagens, a qual se tornou parte essencial de sua ética em campo, teve início no cinema de Jean Rouch com as filmagens de 'Bataille sur le grand fleuve' (1950), filme que mostra uma caça a hipopótamos no rio Níger, realizado durante uma expedição doutoral do próprio Rouch. Portanto, para Rouch, não se tratava de ir até a África 'roubar' informações sobre as diferentes culturas, mas de desenvolver uma forma de conhecimento antropológico que fosse possível de ser acessado pelos próprios nativos, algo possibilitado pelas imagens fílmicas. Assim sendo, tendo em vista o contexto de descolonização e formação dos Estados nacionais africanos no qual Rouch realizou alguns de seus principais filmes:

[...] para ele [Rouch], é necessário antes de tudo transformar essa disciplina que ele identifica como "filha mais velha do colonialismo", para que o conhecimento adquirido possa garantir não a sujeição das populações estudadas ao sistema hegemônico, mas a sua libertação, a possibilidade de 
perpetuação das diferenças apesar do movimento de homogeneização (SZTUTMAN, 2004, p. 52-53).

Essa questão da antropologia compartilhada também dava a possibilidade de se ter acesso às vozes dos nativos e às suas opiniões acerca das imagens dos filmes. Dois exemplos dessa prática são os filmes de etnoficção "Eu, um negro" e "Jaguar" (1967), filmes nos quais Rouch acompanhou grupos de migrantes nigerianos na Costa do Marfim e na Costa do Ouro, respectivamente. Em tais filmes foi realizada a subversão dos áudios, isto é, após as filmagens os nativos construíam de maneira improvisada uma narrativa, a qual está presente no filme, enquanto assistiam as imagens gravadas na mesa de montagem, descrevendo suas vidas, seus sonhos, e possibilitando o acesso aos seus imaginários. Paul Henley faz um breve relato sobre o impacto disto, especificamente no caso do filme 'Eu, um negro', em Godard:

\begin{abstract}
Mas o que também impressionou Godard, em comum com a maioria dos outros críticos, não foram apenas os efeitos técnicos e estilísticos que Rouch conseguira com seus métodos informais de improvisação, mas também o fato de ser esta a primeira vez - visto que Jaguar permanecia inacabado e só foi exibido em público na Cinemathèque - que um longa-metragem proporcionou ao público francês em geral a oportunidade de ouvir africanos descrevendo suas experiências de vida em suas próprias vozes (HENLEY, 2009 , p. 91 , tradução nossa). ${ }^{2}$
\end{abstract}

Rouch ainda inova em relação à sua postura diante dos nativos, ou seja, dos sujeitos do filme, os quais se tornam seus amigos, assim como aponta Marco Antonio Gonçalves (2008).

Os nativos eram deixados, durante as filmagens, livres para fazerem e falarem o que quisessem, recorrendo ao improviso, algo que se repete em outros de seus filmes como 'Jaguar' e 'Crônica de um verão'. Vale lembrar aqui que a câmera acompanhava de perto cada ação durante o filme, tendo em vista as filmagens sem o tripé. Desse modo, é possível uma maior proximidade entre a audiência e o filme, assim como entre a audiência e as ações retratadas.

A utilização do improviso é uma das principais características dos filmes conhecidos como etnoficção. As etnoficções inserem elementos ficcionais no filme etnográfico, possibilitando que os sujeitos do filme se criem e recriem em frente à câmera. Além disso, a subversão dos áudios acrescenta uma maior complexidade a essa categoria, possibilitando um maior acesso aos imaginários, fantasias e sonhos dos nativos, assim como suas próprias

\footnotetext{
${ }^{2}$ But what also impressed Godard, in common with the majority of other critics, was not only technical and stylistic effects that Rouch had managed to achieve by his informal, improvisational methods but also the fact that this was the first time - given that Jaguar remained unfinished and had only been shown in public in the Cinemathèque - that a feature film had provided general French audiences with the opportunity to hear Africans describing their life experiences in their own voices (HENLEY, 2009, p. 91).
} 
perspectivas sobre os filmes. Dessa forma, como é colocado por Marco Antonio Gonçalves ao analisar 'Eu, um negro':

Era o que Rouch queria mostrar, este plano do pensamento das pessoas, de seus dramas, de como viviam aquela realidade a partir da deliberada ficção. E em seu filme as pessoas constroem pela palavra o que são ou o que pensam ou imaginam ser, construindo um mundo a partir desses universos imaginativos que parece tão real como o dia a dia do trabalho no porto carregando sacos. Rouch, assim, pode etnografar imageticamente as ficções e as imaginações destes personagens sem, necessariamente, colocar a ficção em disputa com a realidade (GONÇALVES, 2008, p. 114-115).

É necessário dizer que tal filme representa a maior aproximação entre Rouch e o estilo fílmico da Nouvelle Vague, apresentando o modelo inicial para os cineastas da nova geração, fornecendo todas as características citadas anteriormente:

O modelo inicial é encarnado pelos filmes de Jean Rouch depois de $E u$, um negro (1958). Rouch será o mais fiel a esse procedimento ao longo dos anos 1960, com filmes como La Pyramide Humaine (1959) e La chasse au lion à l'arc (1965). Essa lógica conduz à um média-metragem experimental, $L a$ Punition, com público bem restrito, mas que exercerá influência considerável sobre os filmes de Rohmer dos anos 1970 e 1980. Ela está na origem de uma das obras mais fortes do cinema dos anos 1960: Gare du Nord, curta-metragem realizado por Jean Rouch para o manifesto coletivo Paris vu par... em 1965 (MARIE, 2011, p. 66).

Assim, após a realização de 'Eu, um negro', fica clara a aproximação entre Jean Rouch e o modelo fílmico encarnado e defendido pelos autores da 'Nouvelle Vague', mesmo que as características de tal modelo não ocorressem todas simultaneamente nos filmes dos realizadores franceses.

Ademais, também é necessário dizer que, tendo em vista a subversão das fronteiras entre ficção e realidade, o cinema rouchiano, mais especificamente no que se refere às performances espontâneas dos indivíduos em 'Os mestres loucos', filme que mostra um ritual de possessão Hauka realizado por migrantes nigerianos na Costa do Ouro, causou certos malentendidos, como pode ser notado pela perspectiva de Claude Chabrol, um dos principais autores da 'Nouvelle Vague', acerca das performances dos sujeitos fílmicos:

A famosa frase proferida por Rouch que afirma que a "ficção é o único modo de penetrar a realidade" sintetiza o modo como pensava a própria etnografia, o que levou a mal-entendidos como o ocorrido com o cineasta francês Claude Chabrol que procurou o distribuidor do filme Os mestres loucos e disse-lhe: "Quero encontrar com Jean Rouch porque ele é um fantástico cineasta. Que incrível! Como ele pôde dirigir atores daquele modo?". Chabrol pensava que Os mestres loucos era uma ficção e não um documentário (ROUCH; MARSHALL; ADAMS, 2003, p. 192; CAIXETA 
DE QUEIROZ, 2004, p. 123 apud GONÇALVES, 2008, p. 71, grifo do autor).

Tal filme acabou por demonstrar a limitação do controle que o realizador possuía sobre as imagens do filme, uma vez que o próprio Rouch não controlava a forma como aquelas imagens seriam recebidas. Isto fica claro quando se leva em consideração os ocorridos após a primeira exibição do filme, ainda sem a voz de Rouch elucidando o ritual em questão:

As luzes se acendem na sala de projeção do Museu do Homem. A plateia está atônita depois de assistir aos apenas vinte e sete minutos do filme. Alguns africanos presentes declaram que as imagens vistas são uma afronta à sua dignidade, que elas apresentam os nativos como selvagens. Marcel Griaule (orientador de Rouch) pede, então, que Rouch destrua o filme: aquelas imagens não poderiam ser veiculadas, visto que eram demasiadamente perigosas (SZTUTMAN, 2009, p. 232).

Assim sendo, o que foi possível perceber foi que aquelas imagens poderiam ser interpretadas de diferentes formas de acordo com as experiências, memórias e subjetividades dos mais diversos espectadores.

Após essa primeira exibição, o filme ficou restrito a certos circuitos de cinema. Além disso, outra interpretação, que justifica essa restrição ao filme, se refere ao uso das imagens com fins racistas, de modo que elas poderiam ser utilizadas para demonstrar que os povos africanos eram selvagens, algo, inclusive, totalmente oposto ao pensamento de Jean Rouch. O filme também apresenta imagens que podem chocar aqueles que as assistem, como a cena clímax na qual os nativos sacrificam um cão e o comem.

A partir dessas características e conceitos desenvolvidos em sua obra fílmicoetnográfica, Jean Rouch acabou por trazer questões epistemológicas para o interior da discussão. Tais questões se referem à subversão de fronteiras referentes às categorias usualmente utilizadas pela antropologia: realidade/ficção; objetividade/subjetividade; entre outros.

Tais categorias estão presentes na história do cinema etnográfico mesmo antes de Rouch, uma vez que a antropologia, em busca de sua consolidação como ciência e em busca de objetividade científica, procurou se afastar de conteúdos fílmicos, por considerá-los muito subjetivos e ficcionais, o que contrariaria os princípios do pensamento científico.

Entretanto, Rouch se afasta dessa visão dualista do mundo. Para ele, a ficção e a realidade, assim como a objetividade e a subjetividade, não são categorias antagônicas, mas fazem parte do mundo, coexistindo, o que pode ser exemplificado pelo fato de Rouch 
considerar a ficção como o único modo de penetrar a realidade. Desse modo, a inserção de elementos ficcionais em seus filmes etnográficos, e mesmo de elementos subjetivos, não os torna menos científicos, nem faz com que a objetividade desapareça, mas possibilita o acesso à voz do outro, à voz do africano e seus imaginários, seus sonhos e suas angústias, além de possibilitar o acesso a uma realidade que não existiria não fosse pelo exercício cinematográfico.

\section{Considerações finais}

A obra fílmico-etnográfica de Jean Rouch acaba por possibilitar mudanças de paradigma para o pensamento antropológico, podendo ensejar a superação do caráter colonialista da disciplina, como demonstra Hikiji:

Marco Antonio Gonçalves contrapõe duas visões de antropologia - a de Marcel Griaule e a de seu teimoso orientando. Conhecimento, para Rouch, não pode ser mais um segredo roubado [como o era para Griaule] para ser mais tarde consumido nos templos ocidentais de conhecimento. "É o resultado de uma busca interminável onde etnógrafos e etnografados se encontram num caminho que alguns de nós já chamam de "antropologia compartilhada", diria Rouch (GONÇALVES, 2008, p. 157 apud HIKIJI, 2013, p. 116).

Desse modo, no caso de Rouch, o outro estudado deixa de ser apenas um objeto de pesquisa para se tornar sujeito "e, antes de tudo, um amigo em potencial" (GONÇALVES, 2008 , p. 21), tendo a câmera de filmar como mediador desta relação estabelecida entre pesquisador e pesquisado, entre realizador e personagem.

Mergulhar nos filmes de Rouch nos permite de fato uma aproximação com alguns de seus amigos africanos. Nas etnoficções, seus sonhos, ideias e questionamentos nos parecem por vezes tão familiares. Nos filmes "etnomusicológicos", alguns deles realizados em parceria com Gilbert Rouget, a sensação inicial de estranhamento - embaralhamento musical de uma polirritmia tão densa para nossos ouvidos - vai sendo substituída por uma quase compreensão de pequenas estruturas, sobreposições; percebemos a música Dogon por meio dos olhos, ouvidos e do corpo de Rouch. Em suas abordagens da possessão, temos a "força" da imagem que Luc de Heusch mencionou - imagens por vezes "perigosas", como pensadas por Renato Sztutman (2009) (HIKIJI, 2013, p. 118-119).

Além disso, é importante ressaltar que, além das ideias de antropologia compartilhada e etnoficção, Rouch apresenta uma nova perspectiva, influenciado por Flaherty e Vertov, sobre o estatuto da verdade, se tratando não de uma verdade no cinema, mas sim de uma verdade do cinema, a qual só pode ser alcançada por este meio. Para uma maior compreensão 
dessa ideia é preciso levar em consideração a utilização da subversão dos áudios e a inserção de elementos ficcionais, os quais, para Rouch, não se encontram em antagonismo com a noção de realidade.

O que Jean Rouch buscou mostrar em seus filmes foi uma África em um contexto em que os indivíduos se encontravam presos entre a tradição e a modernização, o que fica exemplificado, por exemplo, por 'Os mestres loucos' e pelos seus filmes de etnoficção. Neste contexto desenvolveu um cinema e uma etnografia inovadores para sua época, os quais buscavam mostrar os sonhos dos sujeitos do filme, além de construir através do acaso e do improviso, sem a utilização de roteiros, uma narrativa que representaria a construção de uma realidade que não existiria se não fosse por intermédio da câmera.

Entretanto, as inovações oferecidas por Rouch acabaram por chamar a atenção mais dos jovens cineastas da 'Nouvelle Vague' do que da academia e, consequentemente, dos antropólogos, o que pode ser explicado pela distância mantida pela academia em relação a conteúdos imagéticos. Em relação a sua recepção pelos novos realizadores franceses, JeanLuc Godard, grande admirador dos trabalhos rouchianos, chegou a considerar Rouch como o responsável por salvar o cinema francês:

Godard ficou particularmente impressionado com os efeitos que Rouch conseguira obter simplesmente por contar com a improvisação de atores não profissionais. Enquanto outros, como os neorrealistas italianos, Pirandello e Stanislávski, procuraram obter tais efeitos por meio de cálculos cuidadosos, Rouch os alcançou confiando no acaso. Jogando com o fato de que em francês o nome de Joana d'Arc é escrito como Jeanne, a forma feminina de Jean, Godard declarou que, como a heroína nacional, Rouch viria em socorro, talvez não da França, mas certamente do cinema francês, abrindo a porta para uma maneira completamente nova de fazer filmes (HENLEY, 2009, p. 91, tradução nossa). ${ }^{3}$

Portanto, Jean Rouch apresentou, com seu cinema etnográfico, possibilidades para a antropologia, tanto em relação a questões estéticas como questões epistemológicas e éticas, as quais permanecem desconhecidas por muitos e que poderiam ser aplicadas para estabelecer diálogos e relações com o outro, com o diverso, possibilitando que os mesmos sejam vistos e ouvidos. Além disso, também apresentou oportunidades para o cinema, fornecendo subsídios para um novo modo de fazer cinema, tal como dito por Godard.

${ }^{3}$ Godard was particularly struck by the effects that Rouch had managed to achieve simply by relying on improvisation by nonprofessional actors. Whereas others, such as the Italian Neorrealists, Pirandello, and Stanislavsky had sought to achieve such effects by careful calculation, Rouch had achieved them by trusting to chance. Playing on the fact that in French the name of Joan of Arc is written as Jeanne, the female form of Jean, Godard declared that like the national heroine, Rouch would come to the rescue, not of France perhaps, but certainly of French cinema, by opening the door on a completely new way of making films (HENLEY, 2009, p. 91). 
AGRADECIMENTOS: Este artigo surgiu durante o processo de pesquisa de mestrado intitulado 'Jean Rouch: um estudo sobre seu fazer fílmico-etnográfico'. Tal projeto é financiado pelo Conselho Nacional de Desenvolvimento Científico e Tecnológico (CNPq), processo 132811/2020-0. Agradeço ao meu orientador, Prof. Dr. Edgar Teodoro da Cunha, pelas oportunidades de pesquisa oferecidas durante minha trajetória acadêmica até aqui.

\section{REFERÊNCIAS}

BARBOSA, A.; CUNHA, E. T. (Org.). Antropologia e imagem. Rio de Janeiro: Jorge Zahar Editora, 2006.

GONÇALVES, M. A. O real imaginado: etnografia, cinema e surrealismo em Jean Rouch. Rio de Janeiro: Topbooks, 2008.

HENLEY, P. The adventure of the real: Jean Rouch and the craft of etnographic cinema. Chicago; London: University of Chicago Press, 2009.

HIKIJI, R. S. G. Rouch compartilhado: premonições e provocações para uma antropologia contemporânea. Iluminuras, Porto Alegre, v. 14, p. 113-122, 2013.

LESSA, R. O. O sentido da etnografia fílmica compartilhada de Jean Rouch em "Crônicas De Um Verão". Cadernos de Arte e Antropologia, v. 3, p. 91-102, 2014.

MARIE, M. A Nouvelle Vague: Uma escola artística. In: MARIE, M. A Nouvelle Vague e Godard. Campinas: Editora Papirus, 2011.

NICHOLS, B. Introdução ao documentário. Campinas: Editora Papirus, 2012.

NOVAES, S. C. Imagem e ciências sociais: Trajetória de uma relação difícil. In: BARBOSA, A.; CUNHA, E. T.; HIKIJI, R. S. G. (Org.). Imagem-conhecimento: antropologia, cinema e outros diálogos. Campinas: Editora Papirus, 2009.

SZTUTMAN, R. Imagens-transe: Perigo e possessão na gênese do cinema de Jean Rouch. In: BARBOSA, A.; CUNHA, E. T.; HIKIJI, R. S. G. (Org.). Imagem-conhecimento:

antropologia, cinema e outros diálogos. Campinas: Editora Papirus, 2009.

SZTUTMAN, R. Jean Rouch: um antropólogo-cineasta. In: BARBOSA, A. et al (Org.). Escrituras da imagem. São Paulo: EDUSP, 2004. 


\section{Como referenciar este artigo}

MIOTTI, M. O cinema etnográfico de Jean Rouch. Rev. Sem Aspas, Araraquara, v. 9, n. 2, p. 207-219, jul./dez. 2020. e-ISSN: 2358-4238. DOI: https://doi.org/10.29373/sas.v9i2.14544

Submetido em: 07/12/2020

Revisões requeridas: $20 / 12 / 2020$

Aceito em: $15 / 02 / 2021$

Publicado em: 01/03/2021 